\title{
Editorial
}

\section{Students' Engagement}

\author{
Piryani Rano Mal \\ Editor, JMCJMS
}

Students' engagement must begin early in the university or professional college. The attention must be paid to the development of both social and academic relationships between, faculty, staff and students. Students' engagement means the time, efforts and energy students commit, devote and dedicate to undertakings andactivities that are related to the anticipated outcomes of a university, college or institution and what institutions ensure to encourage students to participate in activities such academic, social etcInstitutions (universities or professional colleges) achieve and attain their development, growth,status and reputation from the performance of students, hence, students' engagement supports and facilitate in establishing a good rapport between students and faculty members. So, the students'participation must be ensured in the development of the vision of the institutions, in the committees of the institutions, especially in the development of policy guidelines, and the accreditation process $[1,2]$.
Bukhari YR et al. mentioned four essential points identified by Kahu (2013) that defines students' engagement: 1) behavioralfocusing on student behavior and effective teaching practice; 2) psychological- focusing on the individual internal process of engagement including behavior, cognition, emotion and the will to succeed; 3) socialcultural- focusing on the impact of the broader social, cultural and political context; and 4) holistic- attempts to combine the strands $[1,3]$.

Students' engagement is part of the ASPIREto-Excellence initiative launched by the international association for medical education in Europe (AMEE) in 2012. This initiative focuses on recognizing and rewarding excellence in teaching and learning in medical, dental and veterinary schools.This initiative has developed four criteria and subcriteria for a school/program to be regarded as achieving excellence in student engagement. The school/program is expected to demonstrate student engagement in the following four criteria: 1) Students' 
engagement in policy and decision-making activities at the school/program; 2)Students' engagement in the provision and evaluation of the school's education program; 3) Students' engagement in the academic community and; Students' engagement in the local community, in extracurricular activities, and in-service delivery.For each of the mentioned four criteria of students' engagement, there are sub-criteria for which the school/program has expected to provide evidence [3].

Students' engagement is almost missing in majority of health professional education institutions in South Asia. Authorities must have to focus on this aspect of health professionals' education as students and faculty should work together as partners in the new era of modern health professions education in twenty first century where the technology plays a vital role in promoting health professions education besides existing approaches.

\section{REFERENCES}

1. Bukhari YR et al. Perception of medical students regarding excellence in students' engagement: a multicenter Saudi Arabian perspective. Advances in Medical Education and Practice 2019:10 849854
2. Patricio M. The ASPIRE initiative: excellence in student engagement in the school. EducMéd. 2016;17(3):109-114. doi:10.1016/j.edumed.2016.07.003

3. ASPIRE-to-Excellence Award. The Association for Medical Education in Europe (AMEE). Available from: https://amee.org/ awardsprizes/aspire-award. Accessed Jan 12, 2019.

Correspondence to: Piryani Rano Mal Professor and Head of Department of Internal Medicine, Universal College of Medical Sciences, Bhairahawa, Nepal

Email: rano.piryani@gmail.com Cell No: 00977-9841269522 